\title{
Types of Narration in the Text of J. K. Rowling's Tales
}

\author{
Dr. Elena Solodova \\ Sevastopol State University
}

*Corresponding Author: Dr. Elena Solodova, Sevastopol State University

\begin{abstract}
The article focuses on the research of types of narration in the text of $J$. K. Rowling's tales. Such compositional speech forms as description, reasoning, dialogue, inner monologue are revealed. The quantitative analysis of frequency of use of each compositional speech form is presented in the article. It is shown that the prevailing of particular type of compositional speech forms depends upon genre peculiarities of the tales' text.
\end{abstract}

Keywords: compositional speech forms, description, reasoning, dialogue, inner monologue.

The relevance of the work is determined by the popularity which the tales of the English writer have gained all over the world, the increased interest to the study of the postmodern texts in whole and texts of tales in particular as well as by the general tendency towards the integrated research of the lingual phenomena in order to explain its formal, content-related and meaning-related aspects.

The aesthetically stipulated use of the expressive linguistic means is embodied in the composition of the artistic work: it is the composition where the dynamically exposed image of the world is released in the change and alternation of different forms and types of speech [8, p. 80], or compositionalspeech forms (types of narration) $[3$, p. 78-84; 5; 6]. The aim of this article is to reveal and describe types of narration in the text of J. K. Rowling's tales.

The contexts formed on the basis of the literary and colloquial speech allow to apply narration specific for the genre of literary tale performed by such compositional speech forms as description, reasoning, dialogue, inner monologue. Moreover, the reasoning and inner monologue provide the realization of the psychological constituent of tale's text.

The description as the compositional speech form of the evolution of narration is the horizontal or synchronous cut off of the phenomena depicted [6, p. 23]. It is connected with the retardation of action, which is determined by the development of the subject-figural aspect of narration incorporating the introduction of the elements of the surrounding or character portrayal, in particular, depiction of portrait characteristics of characters, etc. This compositional speech form contains the attributes and features promoting to create "completed presentation of a person, subject or phenomenon" [1, c. 202].

In the analyzed tales the description according to its theme characteristics is divided in to two main groups: the description of the space and the description of characters. The data of the qualitative analysis of the corresponding descriptive fragments show the domination of character description over space description. This, in its turn, prove the fact that the artistic prose as well as the prose of tales is considerably less concentrated on the description of space, in which the character appear, than on the description of the characters themselves [3, p. 79]. Taking as the basic value the quality of all descriptive fragments we see that only quarter of them $(25 \%)$ is aimed at description of space continuum (see picture 1).

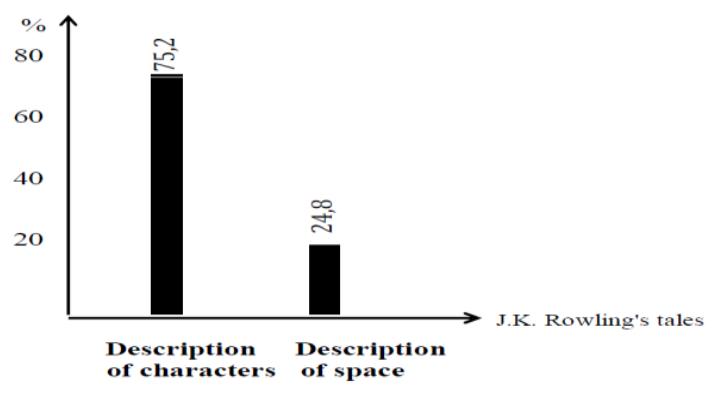

Picture1. Specific Gravity of Character Description and Space Description of J.K. Rowling'sTales 


\section{Description OF Characters of SPACE}

The next type of narration is the description as the way of evaluation of what is depicted. The evaluation of some characters is conveyed by the description of their appearance, portrait characteristics as well as behavior.Evaluativeattitude is formed while depicting aunt Petunia "who had nearly twice the usual amount of neck". However this defect she uses in her own purposes when traces her neighbors and eavesdrops their talk. The portrait characteristics is accompanied by the nominative units expressing the evaluative attitude towards what is depicted (craning over, spyingon, bony and horse-faced, twice the usual amount of neck, whipped around, peered intently out):
Aunt Petunia, who had nearly twice the usual amount of neck, which came in very useful as she spent so much of her time craning over garden fences, spying on the neighbours[v. I; p. 7].Aunt Petunia, who was bony and horse-faced, whipped around and peered intently out of the kitchen window. Harry knew Aunt Petunia would simply love to be the one to call the hotline number [v. III; p. 19].

Such desriptions are typical for the analyzed taless in cethey provide the image of the foster parents as mercantile, hypocritical and greedy. The description of this type constitutes $23 \%$ from the total quality of textual fragments depicting the main characters of the tales.

The next type of narration presented in the tales is reasoning. The content of this compositional speech form possesses generalized cause-and-effect meaning based on the whole or reduced conclusion in the result of which time situation substituted by logical situation appears to be neutralized [6, p. 24]. (Compare: "According to its content reasoning has timeless, global, generalized nature" [2, p. 172]).However, being textual category, but not logical in its pure form, reasoning as the compositional speech form in the speech flow undergoes some changes, namely: message, i.e. judgment, on the base of which conclusion is made can be either in the form of presupposition, previous knowledge common for culture bearer, or can be earlier mentioned in the text [6, p. 52]. The analysis of the reasoning of the analyzed tales proves that the conclusion is presented in them as it is without being excluded by rigid logical formula. It is explained by the fact that being ontologically oriented towards generalization the reasoning uses definite plot event, character, conflict as starting point for universal conclusion [Ibid, p.25].

In J.K .Rowling 's tales characters's speech based on reasoning is not dominant since the work itself is ofcused mainly on children's orteen-ager's audience. Nevertheless, in the fifth book of tales reasoning reflecting different directions of movement of thought of the author is realized in the speech of not only main character but other characters as well. Reasoning acts in the form of statements in the speech of the director of the school of wizards professor Dumbldore. Comprehending the reasoningof Dumbledore, the main character attempts to separate right from wrong, true from false:
"Youmightask - andwithgoodreason - whyithadtobeso. Why could some wizarding family not have taken you in? Many would have done so more than gladly, would have been honored and delighted to raise you as son. 'My answer is that my priority was to keep you alive. You were in more danger than perhaps anyone but I realised. Voldemort had been vanquished hours before, but his supporters - and many of them are almost as terrible as he - were still at large, angry, desperate and violent. And I had to make my decision, too, with regard to the years ahead. Did I believe that Voldemort was gone for ever? No.I knew not whether it would be ten, twenty or fifty years before he returned, but I was sure he would do so, and I was sure, too, knowing him as I have done, that he would not rest until he killed you" [v. V; p. 736].

In the structure of the above given reasoning question-answer type of narration is educed: You might ask why it had to be so. Why could some wizarding family not have taken you in?...My answer is that my priority was to keep you alive; Did I believe that Voldemort was gone forever? No.Such organization of the statement is typical for reasoning [see 5], where ans were have explanatory, discreet nature which belongs to the logical thinking [Ibid, p. 169]. From the point of view of the syntax long sentences with complicated structure incorporating two or more subject-predicate group 
are typical for reasoning [Ibid; p. 182]. Thus, the last sentence in the above given fragment numbers nine subject-predicate pairs:Iknew, it would be, he returned, I wassure, he would do, I was, I have done, he would not rest, he killed.The conclusion of the analyzed fragment, which is obligatory for the given compositional speech form is easily traced[2, p. 171] (he would not rest until he killed you).

According to its frequency "reasoning" as compositional speech form is not do minantand constituentsonly $12,8 \%$ from the total amount of all composition al speech form sanalyzed in J.K. Rowling'stales (see picture 2).

Dialogueis prevailed type of the artistic narration in J.K. Rowling'stales. Itprovidesease of narration typical for the genre of literary tale [7, p. 46].Since the tale about Harry Potter is focused on teenagers, the dialogues are often presented as short and uncompleted sentences:

'Hang on, I think I remember him saying something about it,' said the other twin.

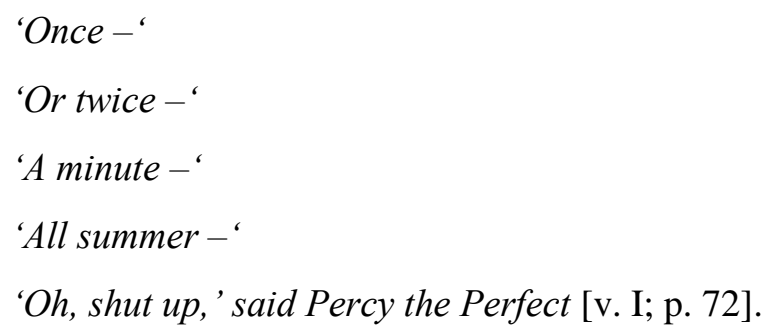

Dialogue is compositional speech form is them ost frequentand comprises $42,6 \%$ from the total quantity of all compositional speech for msin the text of J.K. Rowling'stales (seepicture 2).

Inner monologue is the main compositional speech form in which inner speech is presented [5, p. 166]. This compositional speech form is realized in the fifth book of J.K. Rowling' stales in corporating genre attributes of the psychological novel containing contemplation caused by doubts, discord in the inner world of the main character. Inner monologue terminates plot development: the character contemplates and the action freezes to return into the active phase to the point where it was interrupted by introduction of the inner monologue [Ibid, p. 167]. The signal of the inner speech is author's speech pointing out the thinking process(hethought, thoughtHarry). Graphically this phenomenon is presented by us pension points that convey the transition from one thought to another:
How had he become as nake?' he thought. 'Perhaps he was an Animagus... no, he couldn't be, he would know ... perhaps Voldemort was an Animagus... yes, thought Harry, that would fit, he would turn into a snake of course ... and when he's possessing me, then we both transform ... that still doesn't explain how I got to London and back to my bed in the space of about five minutes ... but then Voldemort's about the most powerful wizard in the world, apart from Dumbledore, it's probably no problem at all to him to transform people like that [v. V; p. 436].

Together with unfold textual forms of inner speech in the text of tales about Harry Potter there are also unexpanded forms:

He felt as though the memory of it was eating him from inside. He had been so sure his parents were wonderful people that he had never had the slightest difficulty in disbelieving the aspersions Snape cast on his father's character.

'Yeah, well, look what Sirius was like himself, said a nagging voice inside Harry's head ... he was as bad, wasn't he?'

Harry tried to make a case for Snape having deserved what he suffered at Jame's hands: but hadn't Lily asked, 'What's he done to you?' And hadn't James replied, 'It's more the fact that he exists, if you know what I mean.' Hadn't James started it all simply because Sirius had said he was bored?' he thought [v. V; p. 575-576].

In the given textual fragment the inner speech presented in the sentenceYeah, well, look what Sirius was like himself, said a nagging voice inside Harry's head ... he was as bad, wasn't he? Fix 
esimmediate emotional reactions of the character on the events of the outer world. Such small in clusions of the inner speech [5, p. 168] of the main character describes his emotional reaction on unpleasant facts about his father which became known to him.

In nermonologue as the compositional speech form is less frequent in the text of J.K. Rowling's tales and constitutes $62 \%$ from the total amount of all analyzed compositional speech forms in the text (see picture 2).

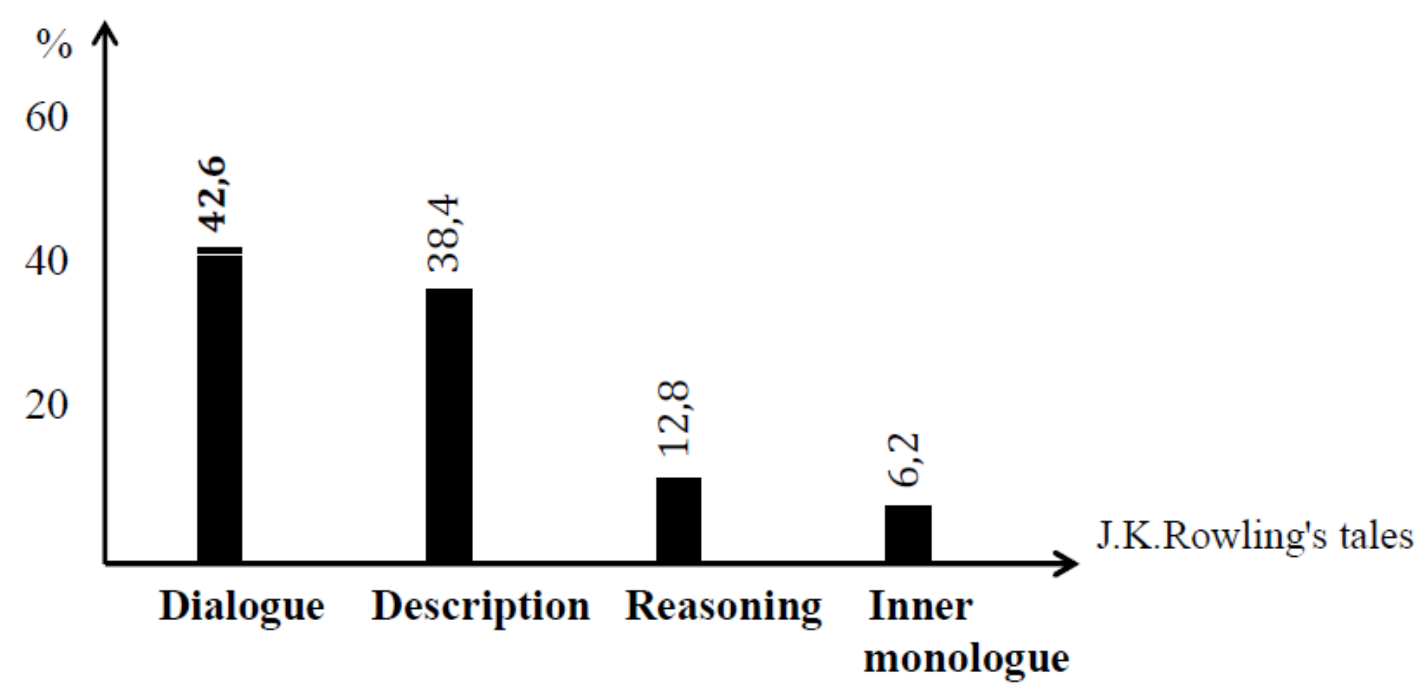

Picture2. Specific Gravity of the Compositional Speech Forms: "Dialogue", "Description", "Reasoning", "Inner Monologue" In the Text of J.K. Rowling's Tales

\section{DiAlogue, DeSCRIPTION, REASONING , INNER MONOLOGUE}

Numeral data received from our research show that dialogue is them ost frequently used compositional speech form, which accounts fornearly half of the total amount, i. e. 42,6\%. "Description" as the compositional speech form takes the second place with 38,4\%. "Reasoning" comprises in significant part of all compositional speech forms equal 12,8\%. "Inner Monologue"constitutes only 6,2\%.

So, the analyzed types of the compositional speech forms perform in the text of the tales such functional tasks as the development of subject-figural aspect of narration incorporation the introduction of the elements of the surrounding or character portrayal, conveyance of the ironic author's attitude towards characters. Moreover, compositional speech form conveys the emotional states of the character, psychological trials connected with rupture in his inner world, providing the psychological component in the text of the tales.

Further perspective researches may be focused on the revealing of the compositional speech forms in describing the image of the author as well as the image of the characters of the tales.

\section{REFERENCES}

[1] A bramovich A. V. (1996). Peculiarities of he Structure of the Description and its Compositional Role In the Genre of Publicism. Moscow: Nauka.

[2] Babenko L.G.(2004). Linguistic Analys is of the Artistic Text. Moscow: Flinta.

[3] Kalinuk E. A. (2002).Frequency and Structural-Position Characteristics of the Compositional Speech Fragments of the Description of Space. Odessa: National University of Odessa Press.

[4] KozhinA.A. (1982). AboutSingularity of the Artistic Narration. Moscow: Nauka.

[5] Kukharenko V.A. (1988). Interpretation of theText. Moscow: Prosveshchenie.

[6] Roshiyanu N. (1974). The Traditional Formulae of the Tale. Moscow: Nauka.

[7] Sorokotenko O.V. (1995). LiteraryTale: Comparative and typological. Simferopol: Simfe ropol National University.

[8] Vinogradov V. V. (1963). Stylistics. Theory of the Poetic Speech. Poetics. Moscow: USSR Academy of Science Press. 


\section{AUTHOR'S BIOGRAPHY}

Dr Elena Solodova, Department of Foreign Languages, assistant professor, Sevastopol State University

I have a strong background in cognitive linguistics, and English in particular. I have published on aspects of cognitive and general linguistics. My $\mathrm{PhD}$ research is focused on cognitive approach to the literary text. My teaching areas are linguistics, spoken and written language development.

Citation: Dr. Elena, Solodova. "Types of Narration in the Text of J. K. Rowling'S Tales." International Journal on Studies in English Language and Literature (IJSELL), vol 5, no. 10, 2017, pp. 7-12. doi:http://dx.doi.org/10.20431/2347-3134.0510002.

Copyright: (C) 2017 Authors. This is an open-access article distributed under the terms of the Creative Commons Attribution License, which permits unrestricted use, distribution, and reproduction in any medium, provided the original author and source are credited. 